\title{
The Virtual CVD Learning Platform
}

\author{
Milo D. Koretsky, Danielle Amatore, Connelly Barnes and Sho Kimura \\ Department of Chemical Engineering, Oregon State University \\ Corvallis, OR 97331-2702 \\ (541)737-4591, koretsm@engr.orst.edu
}

\begin{abstract}
The Virtual CVD Learning Platform provides a capstone experience in which students synthesize engineering science and statistics principles. They apply Design of Experiments (DOE) in the context similar to that of industry with a wider design space than is typically seen in the undergraduate lab. The Virtual CVD Learning Platform contains a numerical simulation of a chemicalvapor deposition (CVD) reactor and is based on fundamental principles of mass transfer and chemical reaction, obscured by added "noise." The Virtual CVD Learning Platform is available for interested educators; moreover, it is self-contained so that it can be placed with versatility where it fits in a given program's curriculum. While the platform chosen is specific to the microelectronics industry, it is expected the lessons learned may be applied to any process. The software application contains a 3D graphical user interface, the calculation engine, a database, and an instructor interface with integrated assessment tools. A robust assessment plan using a model of cognition based on a modification of Bloom's taxonomy of learning is described. This assessment was implemented in Winter 2006.

Index Terms - chemical engineering education, microelectronics, assessment, evaluation, Design of
\end{abstract}

Experiments

\section{INTRODUCTION}

Proficiency with statistical methodologies such as Design of Experiments (DOE) is an increasingly essential skill for engineers. This requires not only knowledge of statistical concepts related to DOE, but also the ability to integrate this methodology with fundamental engineering principles toward designing and understanding experiments. While many current engineering curricula have not fully adapted to this need in the engineering industry, others are actively seeking ways to remedy this deficiency [1]-[4].

Design of Experiments (DOE) is arguably the most ubiquitous and powerful statistical technique applied to engineering. DOE is a method for systematic planning and conducting experiments in which multiple input variables are systematically changed to observe changes in the outputs of a process. Historically, both science and engineering curricula have emphasized one-factor-at-a-time experiments where one variable (factor) is changed while the others are held fixed. This approach is wasteful and the results can be misleading. Statistically designed experiments provide a more effective and efficient way to learn about and optimize a process. By combining the settings of several factors simultaneously in design arrays, it is possible to isolate the effects of each factor individually. A designed experiment usually requires fewer resources for the amount of information obtained, and the results are more precise since more measurements are used to determine the effect of a given factor. Moreover, the interactions between the factors can be quantified.

Presently, DOE is largely taught to entry-level engineers by industry through in house training programs. Such skills are more appropriate to teach at the university where an educational approach emphasizing fundamentals could provide students with greater depth and adaptability in applying these methods. One constraint, however, is that the curriculum is full and, by and large, successful. The educational challenge then becomes how to integrate statisticsbased topics such as DOE so that they complement the existing educational curriculum and can be fit in. More effective methods are needed to allow students to integrate statistics and DOE into their engineering studies.

The undergraduate laboratory has been demonstrated to provide an effective means of teaching DOE through experiential learning [5]. However, lab experiments are expensive and time consuming; hence, there is a constraint on the proportion of topics in the curriculum that can realistically be introduced in the lab. University teaching labs can also be limited by their equipment capability. Ideally, a student would have a rich experience in DOE before entering senior lab which they could reinforce by creatively applying DOE to real measurements. Often, however, the bridge between what is taught in an engineering statistics class and what is required in the lab is weak.

Numerous computer resources have been developed to reinforce knowledge and understanding of statistics. These applications have evolved from forms that are quite similar to conventional printed material to the development of interactive simulations that give students a hands-on learning experience of specific statistics concepts, e.g., the central limit theorem or sampling distributions [11]. However, integrated capstone experiences for students to apply statistics are not so common.

The development of new teaching methods is enhanced by effective assessment and evaluation. Educational assessment seeks to measure the degree of student learning achieved through an intervention and provides opportunities to improve the effectiveness of the intervention. An effective assessment is built on three critical components: (i) a model of cognition that describes how students become competent in a specific subject domain through perception of the concepts as

October 28 - 31, 2006, San Diego, CA 
presented and the transformation of their knowledge as they process these concepts, (ii) tasks or situations that allow observation of student performance and (iii) an interpretation method to analyze the observational data [6]. The development of an appropriate cognitive model and collection of performance evidence becomes increasingly more difficult as increasingly higher level thinking is required. Several taxonomies and models of learning have been developed and are used to construct models of cognition. One of the first taxonomies of learning was developed by Bloom in 1956. Bloom's taxonomy describes six successively deeper levels of cognition, beginning with acquisition of knowledge and culminating with synthesis and evaluation [7]. Many other models have also been proposed. A recent model developed by Shavelson for specific application to K12 science and math assessment describes a model of cognition that distinguishes between declarative, procedural and schematic knowledge and the transitions between these levels [8].

The method to collect performance evidence must also be specific to the model of cognition required by the educational intervention. Traditional assessment methods, such as quizzes and tests, are effective for measuring the acquisition of facts, concepts and discrete skills. However, educational interventions that require higher order cognitive activity, such as critical and creative thinking, are not as effectively assessed with these methods. Alternatively, performance tasks that are designed to simulate real-world scenarios can be used to assess these higher levels of cognition [9]. The "think-aloud" technique has been used successfully to collect performance evidence in the higher cognitive domain; this technique involves observation of a student during interaction with an intervention while the student verbalizes their cognitions [10].

This paper describes an innovative learning tool, the Virtual CVD Learning Platform. It provides opportunities for student engagement in DOE and engineering science at the analysis, synthesis and evaluation cognitive levels. Additionally, the robust assessment strategy that has been implemented in Winter 2006 is described. A critical aspect of this strategy is the development of a model of cognition based on a modification of the well-established Bloom's taxonomy of learning. The Virtual CVD Learning Platform is available now for use in approved courses. Instructors who are interested in adopting this software into their curriculum can go to the following web page for information:

http://che.oregonstate.edu/research/VirtualCVD

\section{The Virtual CVD Learning Platform}

In an attempt to meet the need for a "capstone" experience that integrates engineering and statistics, we have developed a virtual chemical vapor deposition (CVD) reactor based on a numerical simulation where students learn and then actually apply DOE. The Virtual CVD Learning Platform uses fundamental process simulation in a new and innovative way. Students will use the virtual reactor in exactly the same manner as they would a reactor in industry. They will be tasked with improving and optimizing reactor performance based on DOE. In completing this task, they will need to choose the parameters for each of the runs they perform and choose what measurements they want to make. Their choices have a cost associated with them so there is a realistic economic constraint. The most effective performance will be a balance between optimization of performance and cost. Not only must students learn how to apply DOE, they must also determine when their results are good enough and the reactor is ready for production.

\section{Software Design}

The Virtual CVD Learning Platform contains several components:

- Mathematical model

- 3D graphical student interface (3D client)

- Instructor web interface

- Database

The mathematical model and 3D client are summarized below. In addition, all of the software components are described in detail elsewhere [12].

The deposition of silicon nitride, $\mathrm{Si}_{3} \mathrm{~N}_{4}$, films in a CVD reactor was chosen as a model system to provide students experience with applying DOE. This system has sufficient complexity to warrant a methodological design approach, but also can be qualitatively considered in terms of engineering science fundamentals such as mass transport and reaction kinetics.

The simulation of the Virtual CVD reactor is based on a mathematical model that describes both the mass transfer and chemical reaction that take place simultaneously in a CVD reactor and predicts the local thickness of silicon nitride deposit at all radial locations on any wafer. Since real systems do not deterministically adhere to fundamental models, random process and measurement variation are also added.

By using an analytical model based on engineering principles, the reactor outputs are reflective of the chemical and physical phenomena occurring within the system masked by the variation seen in real processes and measurements. Thus those students who integrate their fundamental engineering science knowledge should be more efficient with the experimental designs. We believe this approach will allow conceptual integration of statistics and engineering science and lead to deeper understanding of both topics. In fact, performing the simulation will motivate students to learn more about the physical science to reconcile why they see the results that they are obtaining; thus, they will learn the theory of reactor operation better as well.

The Virtual CVD Learning Platform front-end is a threedimensional (3D) graphical interface that provides the lookand-feel of a typical semiconductor manufacturing environment. From here, the students can make reactor runs, take measurements that they specify, get output data and determine the cost of their experiments. Figure 1a displays a screen-shot of the CVD furnace bay and Figure 1b shows the furnace console where reactor parameters are set. This frontend goes beyond simply providing a method for students to 
Session T1C

a)

b)

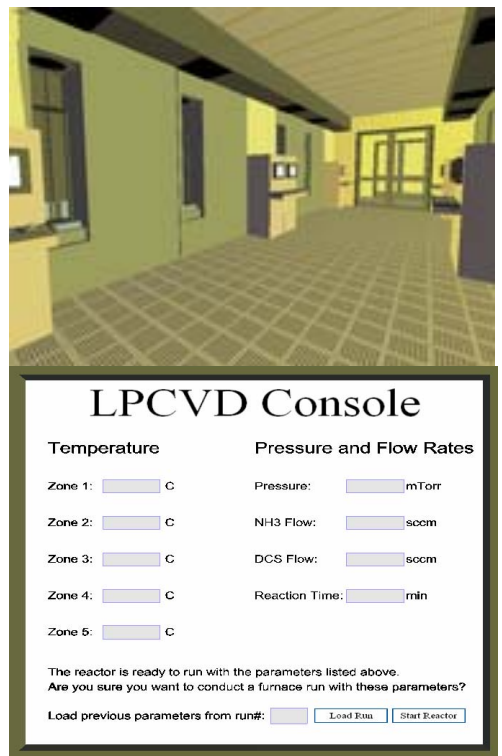

FIGURE 1.

SCREEN SHOTS OF THE VIRTUAL CVD 3D GRAPHICAL USER

INTERFACE : a) CVD REACTOR BAY IN THE VIRTUAL FAB, b)

CVD CONSOLE WHERE STUDENTS INPUT REACTOR PARAMETERS

access the simulation. It also allows students to become familiar with the appearance of a cleanroom. The similarity of the $3 \mathrm{D}$ interface to popular video games allows this learning platform to feel familiar and non-threatening to the student.

\section{Implementation}

The Virtual CVD Learning Platform was used in Winter 2005 and Winter 2006 in a senior-level undergraduate chemical engineering course at OSU, ChE 444, Thin Film Materials Processing. Eight student groups of 3-4 members completed the assignment as the final project for the course. In this assignment, the groups were asked to conduct experiments to determine a process recipe to release to high volume production. The final deliverables were a written report and an oral presentation. Before being granted access to the reactor, each group needed to come up with a written "Preliminary Design Strategy" which was reviewed by the group and the instructor. In order to determine their initial reactor parameters, the students must apply concepts learned in core chemical engineering classes to this open-ended problem. This is a direct indication of their cognitive ability to synthesize. In addition, the students must review course textbook and other references to determine realistic operating conditions; this task gives insight into their critical evaluation skills. The "Preliminary Design Strategy" process ensured that the groups had a well-thought out approach before making runs (in analogy to obtaining management approval in industry). However, evidence from the assessment shows that even with a well-designed DOE, some groups revert to a onefactor-at-a-time experimentation when executing the project.

Beginning in the 2006-2007 academic year, the Virtual CVD Learning Platform will be integrated into the $\mathrm{ChE}$ Capstone Laboratory course (ChE 414). In this way, every $\mathrm{ChE}$ undergraduate at OSU will gain critical experience in the entire cycle of applying experimental design methodology prior to their capstone projects on the real equipment in the lab. The rational for integration is not content specific, i.e., microelectronics processing, but rather it is believed that the process of going through this type of design methodology will provide students with a useful experience that will effectively translate to any experimental design they may face.

The Virtual CVD Learning Platform is designed to ensure ease of transportability and adaptability to different curricular structures. In addition to the classes at OSU, the Virtual CVD Learning Platform will be implemented remotely in Summer 2006 in the Semiconductor Processing and Device Characterization MS Program at the University of Oregon (UO). This internship-based program provides students with BS degrees in Physics and Chemistry background in semiconductor device physics, processing and manufacturing. While it will be implemented in a very different type of program, the Virtual CVD Learning Platform will provide the same function at UO that it does at OSU - it will give students hands-on experience with DOE before they apply it creatively in the lab. The effectiveness of the Virtual CVD Learning Platform in these very different programs will indicate its true transportability and general usefulness to a variety of academic programs nationwide.

As a demonstration of its versatility, the Virtual CVD Learning Platform has been adapted to demonstrate Green Engineering (GE) principles through the GE website maintained by Rowan University [13]. In this problem, the student use the Virtual CVD reactor to minimize the utilization of dichlorosilane within manufacturing and cost constraints, i.e., the student actually practices Green Engineering. This application shows the strength of the Virtual CVD Learning Platform as an educational tool. It can be creatively adapted to fit in and support any number of different curricular structures. It essentially provides a complete system which instructors can use as they need.

\section{EdUCATIONAL OBJECTIVES}

The Virtual CVD Learning Platform is an intervention designed to allow students to achieve the following educational objectives:

1. Design experiments to optimize the performance of a CVD reactor.

- Identify key reactor inputs and determine relationship between input levels and achieved thin film uniformity.

- Design appropriate statistical methodology to optimize the uniformity.

2. Perform virtual experiments, analyze and interpret the results.

- Explain resulting film uniformity in terms of chemical and physical phenomena.

- Analyze film uniformity during experimentation and iteratively modify the experimental design to account for any surprises.

- Explain why any adjustments in experimental design were made and their effect.

October 28 - 31, 2006, San Diego, CA 
3. Synthesize and toggle between statistics and engineering science concepts while applying both in a real-world simulation.

4. Synthesize results in a final written and oral report.

\section{Assessment and Evaluation Plan}

A critical component to the success of this project is the development of an assessment system to evaluate the effectiveness of this tool in promoting higher order thinking skills. A major outcome of the assessment process is to identify and potentially fix any limitations or disadvantages in this teaching tool. The assessment system is based on the evaluation of the educational objectives as well as the transportability of the learning platform.

The evaluation model that best fits the Virtual CVD Learning Platform is one that closely integrates assessment results to improve the design and implementation of this learning platform. Evidence of the development of the cognitive capacity of students requires the design and interpretation of an assessment system that mirrors the ways in which knowledge is developed and applied in the working environment of engineers [6]. The development of an assessment system tied through backwards design to the educational objectives that frame the content and processes of the courses is viewed to be one of the products of this project. In addition, the evaluation plan will measure the transportability of the Virtual CVD Learning Platform to support its use in a variety of engineering and science courses.

\section{Model of Cognition}

A central role of the assessment design is to develop a model of cognition. This model is based on the well-established taxonomy of learning developed by Bloom [7]. Bloom describes learning as a series of successively deeper cognitive capacities, starting from the acquisition of knowledge and culminating with the highest levels of cognitive activity, synthesis of prior knowledge and skills towards a creative outcome and critical evaluation of its value. It is well established that engineers need excellent analytical skills as is actualized by the focus of engineering curriculum on developing problem solving skills. Senior level courses, such as design and lab, require that students synthesize concepts from their core engineering courses and apply to open-ended engineering projects. The development of evaluation skills is less apparent in engineering curriculum; however, the importance of this high level cognitive skill is essential to the success of an engineer. Students must have the ability to critically evaluate both the value of information (especially in the information age) and the validity of their approach.

To model the cognition occurring through interaction with the Virtual CVD Learning Platform, Bloom's taxonomy has been modified as depicted in Figure 2. In this model, synthesis and evaluation are treated as equivalent levels of cognitive depth, representing creative and critical thinking, respectively. These elements are both seen as essential skills needed to

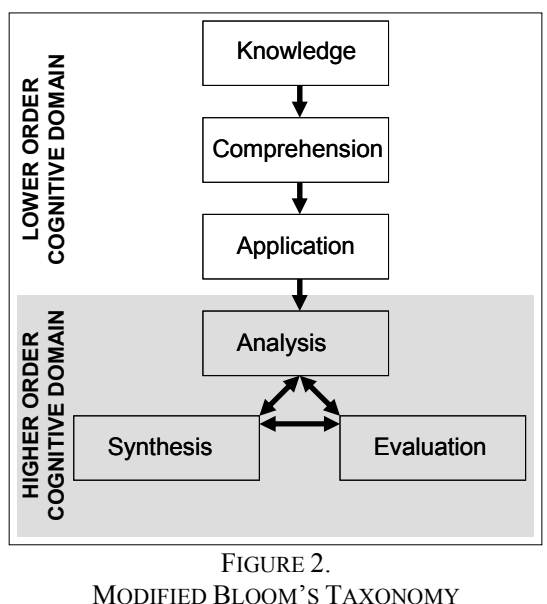

perform successfully. Moreover, the domains of analysis, synthesis and evaluation are connected by double arrows. This representation indicates the importance of being able to smoothly transition between these cognitive domains. In fact, it is hypothesized that not only will the best performers demonstrate activity in these domains, but they will also be able to quickly transition between them. Evidence of cognitive transition between analysis, synthesis and evaluation is measured as part of the assessment.

\section{Think-Aloud Method}

Previous research has shown the value of observing people while they "think aloud" to give insight to their cognitive process, especially in situations where higher order critical thinking ability is needed [8]. Analysis of a "think-aloud" session provides evidence demonstrating a student's cognitive processes. This technique will be utilized in the assessment of the Virtual CVD Learning Platform to aid in the development of a cognitive model. To add insight into the cognitive model, data from "think-aloud" sessions will also be gathered from engineers in industry and from this an expert-novice comparison will be developed.

The "think-aloud" assessment technique was implemented in ChE 444 during Winter 2006. Of the eight student groups, three student groups were selected to participate in the "think-aloud" study. During these sessions, the student groups are observed while working on the Virtual $C V D$ project and their verbalizations are captured for later analysis. In addition, two process engineers from industry were recruited to complete the Virtual CVD assignment and, similarly, their expert cognitions were captured during "thinkaloud" sessions. From this, an expert-novice comparison can be made to aid in the development of a model of cognition. All "think-aloud" sessions were captured with an audiorecording device and transcribed. To analyze the performance data collected during the "think-aloud" sessions, the transcripts were coded using a coding system that applies the modified Bloom's taxonomy shown in Figure 2. The cognitive degree of participant's verbalizations is measured along this cognitive continuum according to the coding matrix shown in Table 1.

October 28 - 31, 2006, San Diego, CA

\section{1-4244-0257-3/06/\$20.00 @ 2006 IEEE}

\section{$36^{\text {th }}$ ASEE/IEEE Frontiers in Education Conference}


TABLE 1.

CODING MATRIX FOR “THINK-ALOUD” ANALYSIS: THE MATIX IS USED TO MEASURE DEGREE OF COMPENTENCY IN ENGINEERING SCIENCE AND STATISTICS. EXAMPLE STATEMENTS DEMONSTRATING MASTERY ARE SHOWN.

\begin{tabular}{|c|c|c|}
\hline & Engineering Science & Statistical Methodology \\
\hline & \multicolumn{2}{|c|}{ Measure of competency } \\
\hline Cognitive Level & $\begin{array}{c}(1) \\
\text { practicing } \rightarrow\end{array}$ & $\begin{array}{c}(1) \\
\text { practicing } \rightarrow\end{array}$ \\
\hline & EXAMPLE STATEMENT OF MASTERY & EXAMPLE STATEMENT OF MASTERY \\
\hline A. Knowledge & $\begin{array}{l}\text { Silicon nitride films are grown from dichlorosilane and ammonia } \\
\text { feed gases. }\end{array}$ & DOE is a statistical method that is used to optimize processes. \\
\hline B. Comprehension & $\begin{array}{l}\text { Growth rates increase with increasing reactor temperature since } \\
\text { reaction rates follow an Arrhenius behavior. }\end{array}$ & $\begin{array}{l}\text { Applying DOE will help you determine the relative effects of the } \\
\text { process inputs and any interactions between inputs. }\end{array}$ \\
\hline C. Application & $\begin{array}{l}\text { Since film thickness increases with temperature, if I increase the } \\
\text { reactor temperature I expect a thicker film. }\end{array}$ & $\begin{array}{l}\text { Given } 9 \text { process inputs, let's select temperature and pressure as the } \\
\text { factors to study in a } 2^{\mathrm{k}} \text { factorial DOE design }\end{array}$ \\
\hline D. Analysis & $\begin{array}{l}\text { At constant reactor temperature, I observe the film thickness } \\
\text { decreases along the reactor. This decrease is caused by a decrease } \\
\text { in reactant concentration. Therefore, I could increase the } \\
\text { temperature along the reactor to compensate for the used reactant } \\
\text { and get a more uniform film. }\end{array}$ & $\begin{array}{l}\text { The graphs of the results from our DOE show that film thickness } \\
\text { changes most with reactor temperature. Therefore, temperature } \\
\text { has the largest impact on film thickness. }\end{array}$ \\
\hline $\begin{array}{l}\text { EI. Synthesis } \\
\text { EII. Evaluation }\end{array}$ & $\begin{array}{l}\text { During my previous design course, I studied a CVD reactor and } \\
\text { determined that a realistic thickness profile across the reactor is } \\
+/-3 \% \text {. Therefore, the } 80 \% \text { uniformity that I am now getting is } \\
\text { probably too low. }\end{array}$ & $\begin{array}{l}\text { During an internship in the paper and pulp industry I used a DOE } \\
\text { to troubleshoot a process with great success. Therefore, I am } \\
\text { going to design, perform and analyze results from a DOE to } \\
\text { optimize this thin film deposition process. }\end{array}$ \\
\hline
\end{tabular}

This coding matrix is used to measure the level of cognition demonstrated by specific verbalizations. In addition, the participant's transition between levels within the higher order cognitive domains - analysis, synthesis and evaluation - were observed and recorded.

In addition, to determine the increase of cognitive ability through the intervention of the Virtual CVD Learning Platform, a pre-assessment was administered before the students started the project. This pre-assessment built on a hands-on lab that the students completed earlier in the term where the entire class worked to characterize a silicon oxidation furnace through experimentation. In an exam question, students were asked to analyze data from this lab and design an experimental strategy to further characterize the furnace. The responses to this pre-assessment question were analyzed with the coding matrix shown in Table 1 .

\section{Assessment through the Instructor Interface}

The Virtual CVD Learning Platform itself provides useful quantitative data about the student's interaction with the learning platform. A summary of all students' interactions with the tool and all raw data is available. These data are available to the instructor through the instructor interface. A summary of the performance for each group is shown in Table 2. This table reports the overall uniformity and standard error off target for each student group. It can be seen that groups can be evaluated both by the efficacy of their process and the cost of the experimentation. The values might vary from the students' reported values because they are not limited to discrete measurement points, but rather calculated by the software to encompass an average of all the films grown without the imposed process and measurement variation. In statistical terms, the value reported to the instructor (as shown in Table 2) is the population based on the student choice of reactor parameters while that reported by the students is a sample based on their measurements. Also, the total cost of the experimentation is reported. The value is based on the number of runs and number of measurements the group has made and is also available in the student interface. The utilization of both feed gases is displayed; a critical measurement of the success of the student's effort to maximize the utilization of dichlorosilane. For each case, the value for each output of the group that has performed the best is denoted in bold.

Another useful assessment tool is analyzing the standard error off target as shown for different axial positions along the reactor as displayed in Figure 3. Interpreting this graph and relating it to the table summarizing student's results, an instructor can assess how well the students optimized the reactor. For example, although Group 7 starts off with only marginal uniformity, their process results in rather consistent monotonically increasing uniformity wafer to wafer, axially up the reactor. Contrarily, Group 6 starts with very similar uniformity, however, the axial effects result in very poor uniformity up the reactor. Group 8 has the best dichlorosilane utilization; however they did not achieve very good uniformity. This demonstrates the challenge of increasing utilization while maintaining uniformity. Again, the uniformity monotonically increases along the axis of the reactor. In some cases, the standard error goes through a

TABLE 2.

SUMMARY OF STUdENT PERFoRMANCE FOR WiNTER 2006

\begin{tabular}{|c|c|c|c|c|c|c|}
\hline Username & Uniformity & StdErr $(\AA)$ & Cost & $\begin{array}{c}\text { DCS } \\
\text { Utilization }\end{array}$ & $\begin{array}{c}\text { Moles } \\
\text { NH3 Used }\end{array}$ & $\begin{array}{l}\text { Time } \\
(\min )\end{array}$ \\
\hline w06group1 & $98.9 \%$ & 13.2 & $\$ 136,175$ & 0.143 & 5.1 & 57.0 \\
\hline \begin{tabular}{|l} 
w06group2 \\
\end{tabular} & $98.7 \%$ & 16.0 & $\$ 80,150$ & 0.063 & 11.6 & 98.0 \\
\hline \begin{tabular}{|l} 
w06group3 \\
\end{tabular} & $98.7 \%$ & 15.2 & $\$ 146,550$ & 0.327 & 6.6 & 149.0 \\
\hline \begin{tabular}{|l|} 
w06group4 \\
\end{tabular} & $94.7 \%$ & 63.2 & $\$ 76,100$ & 0.428 & 5.1 & 57.0 \\
\hline \begin{tabular}{|l|} 
w06group5 \\
\end{tabular} & $98.0 \%$ & 24.4 & $\$ 55,700$ & 0.318 & 2.5 & 128.0 \\
\hline \begin{tabular}{|l|} 
w06group6 \\
\end{tabular} & $96.4 \%$ & 43.3 & $\$ 108,400$ & 0.163 & 4.5 & 20.0 \\
\hline \begin{tabular}{|l} 
w06group7 \\
\end{tabular} & $97.9 \%$ & 24.8 & $\$ 85,625$ & 0.411 & 1.8 & 33.0 \\
\hline \begin{tabular}{|l|} 
w06group8 \\
\end{tabular} & $88.7 \%$ & 135.5 & $\$ 89,375$ & 0.476 & 4.6 & 20.5 \\
\hline Max & $98.9 \%$ & 135.5 & $\$ 146,550$ & 0.476 & 11.6 & 149.0 \\
\hline Mean & $96.5 \%$ & 41.9 & $\$ \$ 97,259$ & 0.291 & 5.2 & 70.3 \\
\hline \begin{tabular}{|l|} 
Min \\
\end{tabular} & $88.7 \%$ & 13.2 & $\$ 55,700$ & 0.063 & 1.8 & 20.0 \\
\hline StdDev & $3.5 \%$ & 41.4 & $\$ 31,014$ & 0.151 & 3.0 & 49.3 \\
\hline
\end{tabular}

October 28 - 31, 2006, San Diego, CA

\section{$36^{\text {th }}$ ASEE/IEEE Frontiers in Education Conference T1C-29}




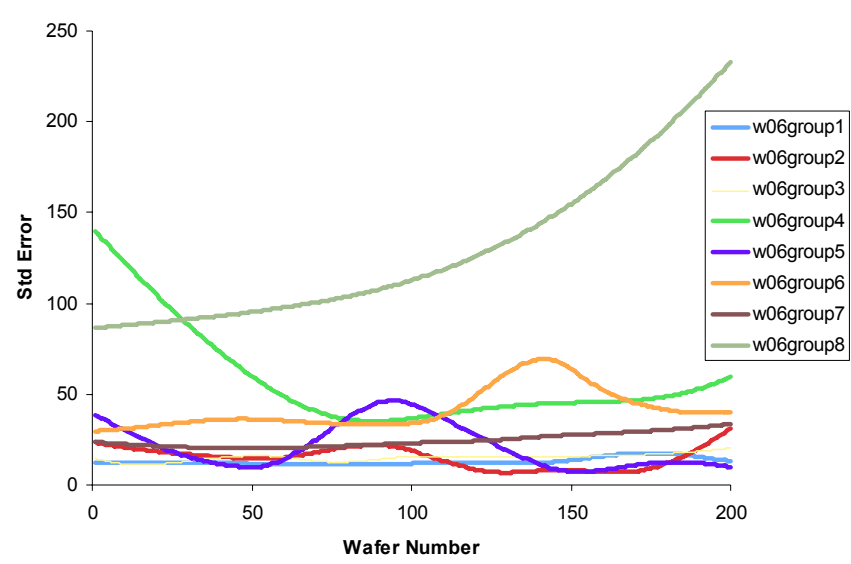

FIGURE 3.

ASSESSMENT TOOL OUTPUT TO INSTRUCTOR - PLOT OF STANDARD ERROR OFF TARGET. SHOWN FOR THE 8 GROUPS USING THE VIRTUAL CVD LEARNING PLATFORM IN WinTER 2006.

maximum along the axis of the reactor such as with Groups 2, 5 and 6. In such a case, the students have not optimized the temperature profile along the reactor. In essence, if a group shows a monotonically increasing profile, it has done as good as it can, given the conditions at Wafer 1 . The only way they can do better is to change conditions at Wafer 1 . On the other hand, groups that show a maximum in this plot have not obtained the optimal axial profile given their choice of conditions at Wafer 1. The assessment data available from the summary table and graph of standard error, both available through the Instructor Interface, provide a complete picture of the student's optimization performance.

\section{CONCLUSION}

The Virtual CVD Learning Platform provides a capstone experience in which the students synthesize engineering science and statistics principles. They apply DOE in the context similar to that of industry with a wider design space than is typically seen in the undergraduate lab. The software application contains a 3D graphical user interface, a calculation engine, an instructor interface, and a database. The calculation engine consists of a mathematical model based on first principles obscured with process and measurement variation. These educational materials will provide a synergy between reinforcing fundamental statisticsbased concepts and the engineering science that is emphasized throughout the curriculum. The Virtual CVD Learning Platform is self-contained so that it can be placed with versatility where it fits in a given program's curriculum, both within ChE departments and in other appropriate disciplines. It is available for use upon request. While the platform chosen is specific to the microelectronics industry, it is expected the lessons learned may be applied to any process; hence its delivery at OSU will change from a topic specific elective course to the required capstone lab. Assessment methods are integrated into the instructor interface. A comprehensive assessment strategy was implemented in Winter 2006 and through this a cognitive model is being developed. Results from this assessment will be used to feedback enhancements to further promote acquisition and smooth transition between the higher order cognitive skills of analysis, synthesis and evaluation.

\section{ACKNOWLEDGMENT}

The authors are grateful for support provided by the Intel Faculty Fellowship Program and the National Science Foundation's Course, Curriculum and Laboratory Improvement Program, Educational Materials Development under grant DUE-0442832. Edith Gummer of the Northwest Regional Educational Laboratory (NWREL) consulted on the assessment design and implementation. Special thanks to Derek Meyers-Graham and Jeff Noffsinger, Computer Science undergraduates at OSU, for their contribution to the 3D graphical user interface. To Robert Hesketh and Stewart Slater of Rowan University for including the Virtual CVD Learning Platform on the Green Engineering web site.

\section{REFERENCES}

[1] Lang, James D., Susan Cruise, Francis D. McVey and John McMasters, "Industry Expectations of New Engineers: A Survey to Assist Curriculum Designers", Journal of Engineering Education, 88, 43 (1999).

[2] Eckert, Roger E., “Applied Statistics: Are Educators Meeting the Challenge", Chemical Engineering Education, (spring, 1996), pp 122.

[3] Dorland, Dianne and K. Karen Yin, "Teaching Statistics to ChE Students", Chemical Engineering Education, (summer, 1997), pp 170.

[4] Hunter, J. Stuart, “Applying Statistics to Solving Chemical Problems”, CHEMTECH, (March 1987), p. 167.

[5] Mills, Jamie D., "Using Computer Simulation Methods to Teach Statistics: A Review of the Literature", Journal of Statistics Education, 10 (2002).

[6] Pelligrino, J. W., Naomi Chudowsky, and Robert Glaser, Knowing What Student Know: The Science and Design of Educational Assessment, National Academy Press: Washington, D.C. (2001).

[7] Bloom, S. Benjamin, Taxonomy of Educational Objectives: The Classification of Educational Goals; David McKay Company, 1956.

[8] Shavelson, Richard, A. Ruiz-Primo, Min Li Maria, and Carlos C. Ayala, "Evaluating New Approaches to Assessing Learning", Center for the Study of Evaluation Report, 2003.

[9] Wiggins, G and Jay McTighe, Understanding by Design, Prentice Hall: New York (2000).

[10] Ruiz-Primo, M. A., S. E. Schultz, M. Li, \& R. J. Shavelson. "Comparison of the reliability and validity of scores from two conceptmapping techniques", Journal of Research in Science Teaching, 38(2), 2001, 260-278.

[11] Ludlow, Douglas K., Kirk H. Schultz and John Erjavec, "Teaching Statistical Design Using a Laboratory Experiment", Journal of Engineering Education, 84, 351, 1995.

[12] Koretsky, Milo, Connelly Barnes, Danielle Amatore, and Sho Kimura, "Experiential Learning of Design of Experiments Using a Virtual CVD Reactor", American Society of Engineering Education Conference Proceedings, June 2006.

[13] Green Engineering Web site: http://nebula.rowan.edu:82/, retrieved on March 18, 2006.

\section{$36^{\text {th }}$ ASEE/IEEE Frontiers in Education Conference}

